\title{
High Origin Causes High Hassle-Anomalous Radial Artery Origin Complicating a Radial Percutaneous Transluminal Coronary Angioplasty
}

\author{
Chirag Dodavenkannavar*, Rajesh Thachathodiyl, Vikrant Vijan \\ Department of Cardiology, Amrita Institute of Medical Sciences, Amrita Vishwa Vidyapeetam University, Kochi, India \\ Email: chiragnichi@gmail.com
}

How to cite this paper: Dodavenkannavar, C., Thachathodiyl, R. and Vijan, V. (2017) High Origin Causes High Hassle-Anomalous Radial Artery Origin Complicating a Radial Percutaneous Transluminal Coronary Angioplasty. World Journal of Cardiovascular Diseases, 7, 207-212.

https://doi.org/10.4236/wjcd.2017.76019

Received: April 13, 2017

Accepted: June 25, 2017

Published: June 28, 2017

Copyright $\odot 2017$ by authors and Scientific Research Publishing Inc. This work is licensed under the Creative Commons Attribution International License (CC BY 4.0).

http://creativecommons.org/licenses/by/4.0/

\begin{abstract}
Since its initial description as a safe and feasible access route for cardiac catheterization, the radial artery has been increasingly used for percutaneous coronary procedures. The transradial approach for percutaneous coronary procedures has the advantage of reduced adverse vascular events. Nevertheless, there are chances of transradial procedure failure due to variation in radial artery anatomy. We report a case of high radial artery origin in a 63 year-old-male patient who was taken up for elective radial percutaneous transluminal coronary angioplasty for in-stent restenosis of proximal left anterior descending artery. Subsequently, there was difficulty in negotiating guide wire and balloons, so imaging of radial artery was carried out which clearly demonstrated a high bifurcating radial origin. This case emphasizes the need for imaging of radial artery to delineate underlying anomalies and identifying patients with unfavorable anatomy when technical difficulties are encountered. Imaging in such a situation helps in planning an appropriate strategy.
\end{abstract}

\section{Keywords}

Radial Artery Abnormalities, Treatment Outcomes, Anomalies, Transradial Approach

\section{Introduction}

The radial artery is increasingly being used for percutaneous coronary procedures. The main advantage over the femoral artery is a reduced risk of vascular complications [1] [2]. This is attributed to the favorable neurovascular anatomy of the radial artery where it runs superficially, separated from major nerves. 
Immediate ambulation and facilitation of day-case intervention also favors the radial approach.

The transradial technique is, however, associated with a significant learning curve even for experienced femoral operators. There are several reasons leading to transradial approach failure like inability to puncture, artery spasm and anatomical variations. The anatomical variations reported include: 1) high-bifurcating radial origin, 2) radial artery loop, 3) extreme radial artery tortuosity, 4) radial atherosclerosis, 5) subclavian tortuosity, 6) anomalous additional vessels, 7) minor bifurcation variations [3]. Radial artery anomalies are relatively common and a cause of transradial procedure failure even for experienced radial operators. We report a case of high radial artery origin in a patient who was taken up for elective radial percutaneous transluminal coronary angioplasty. Retrograde radial arteriography was useful in determining the anomalous origin of radial artery.

\section{Case Report}

A 63-year-old male patient was taken up for elective radial percutaneous transluminal coronary angioplasty for in-stent restenosis of proximal left anterior descending artery stent. Right radial access was obtained and a $6 \mathrm{~F}$ introducer sheath was inserted. Intra-arterial vasodilator $(8 \mathrm{mg}$ nicorandil) and 7500 units unfractionated heparin was administered. A 6F Extrabackup (EBU) guiding catheter was selected. Resistance was experienced while passing the catheter in arm. Left main coronary artery (LMCA) was cannulated and check angiogram was performed. 0.014 inch balance middleweight (BMW) guide wire was selected to cross the LAD. Extreme resistance was noted, while maneuvering the BMW guide wire. Similar resistance was noted while passing the balloon to predilate the proximal LAD lesion. Successive predilatation was not possible due to difficulty in maneuvering the balloons. On withdrawal of balloons from the system, unusual bends were noted in the shaft (Figure 1 and Figure 2). BMW guide wire was withdrawn which also showed multiple bends (Figure 3). Retrograde radial arteriography through the radial artery introducer sheath and a Tig diagnostic catheter showed high origin of radial artery in relation to upper third of humerus. There was also significant spasm of the artery (Figure 4). Radial procedure was aborted and the procedure was completed via transfemoral approach.

\section{Discussion}

Transradial percutaneous coronary procedures have gained in popularity because of reduced access site vascular complications and immediate patient mobilization. Procedural success has been facilitated through technological enhancements and miniaturization of equipment. Reported technical failure for transradial procedures is between $1 \%$ and 5\% [1] [4] [5]. Reasons leading to failure include inability to puncture, artery spasm and anatomical variations. Incidence of first two of these causes is well documented. Higher procedure failure rates are also observed in patients with radial artery anomaly. 
Autopsy studies of upper limb arterial anatomical variation reported a frequency of between $4 \%$ and $18.5 \%$ [6] [7]. When two dimensional ultrasonography and color Doppler were used this figure was 9.6\%, while arteriography studies reported between $7.4 \%$ and $22.8 \%$ [8] [9]. Not only were there wide variations in the occurrence of anomaly, but there were also variations in the pattern of anomalies reported, partly owing to differences in definitions. Figure 5 shows anomaly types and associated failure rates in a study by T.S. Lo et al. [3]. Table 1 compares patient characteristics and procedural data for different radial anatomical patterns in the same study [3].

High bifurcating radial origin is the most common radial anomaly with a reported incidence of $7 \%$. The site of anomalous origin is determined with reference to the intercondylar line of humerus, which is a fixed line representing the proximal border of the antecubital fossa. Bifurcation of brachial artery proximal

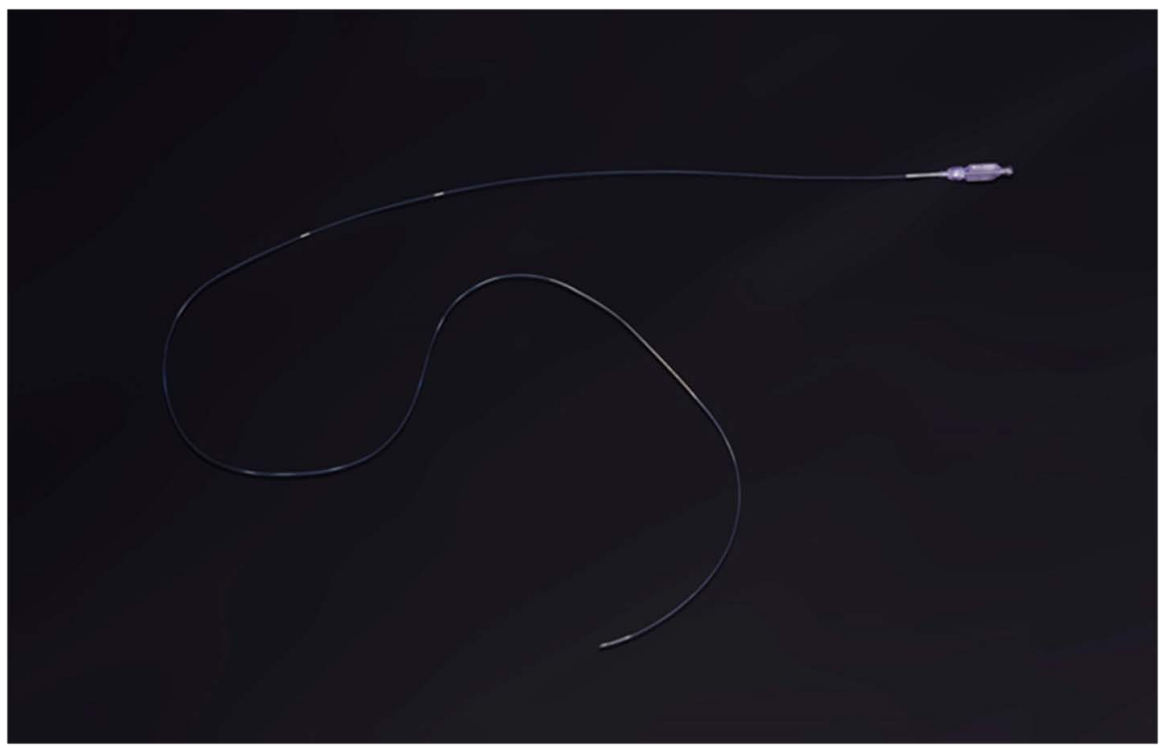

Figure 1. Deformed balloon shaft 1.

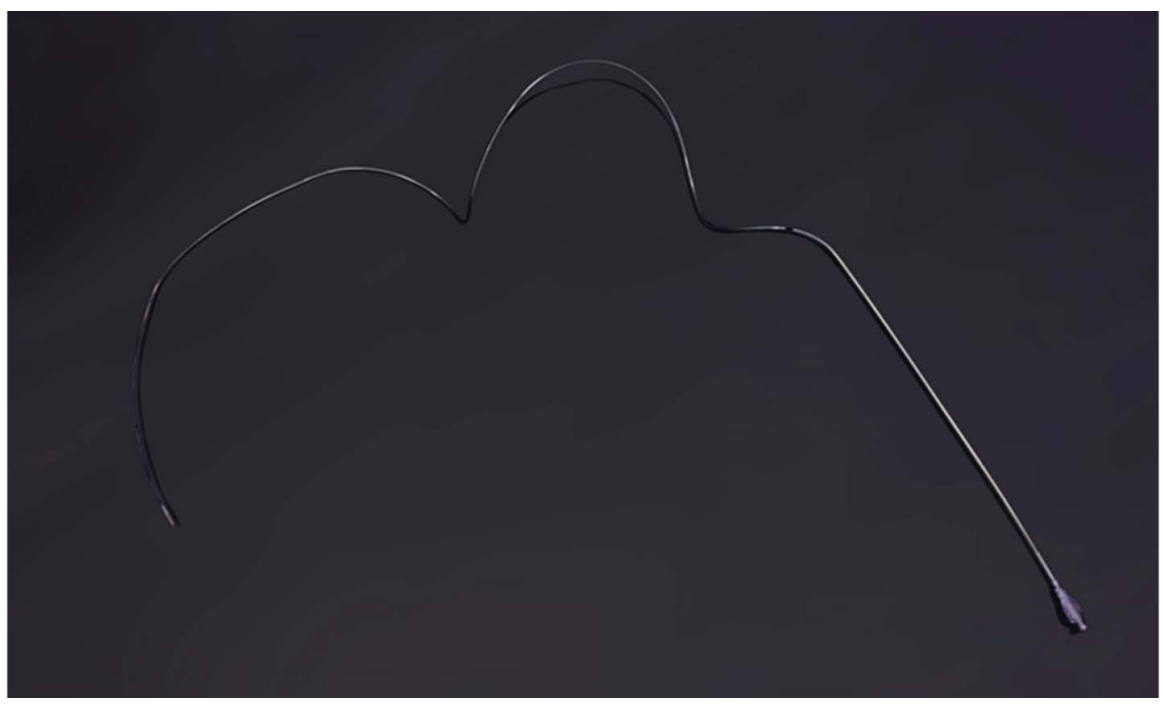

Figure 2. Deformed balloon shaft 2. 


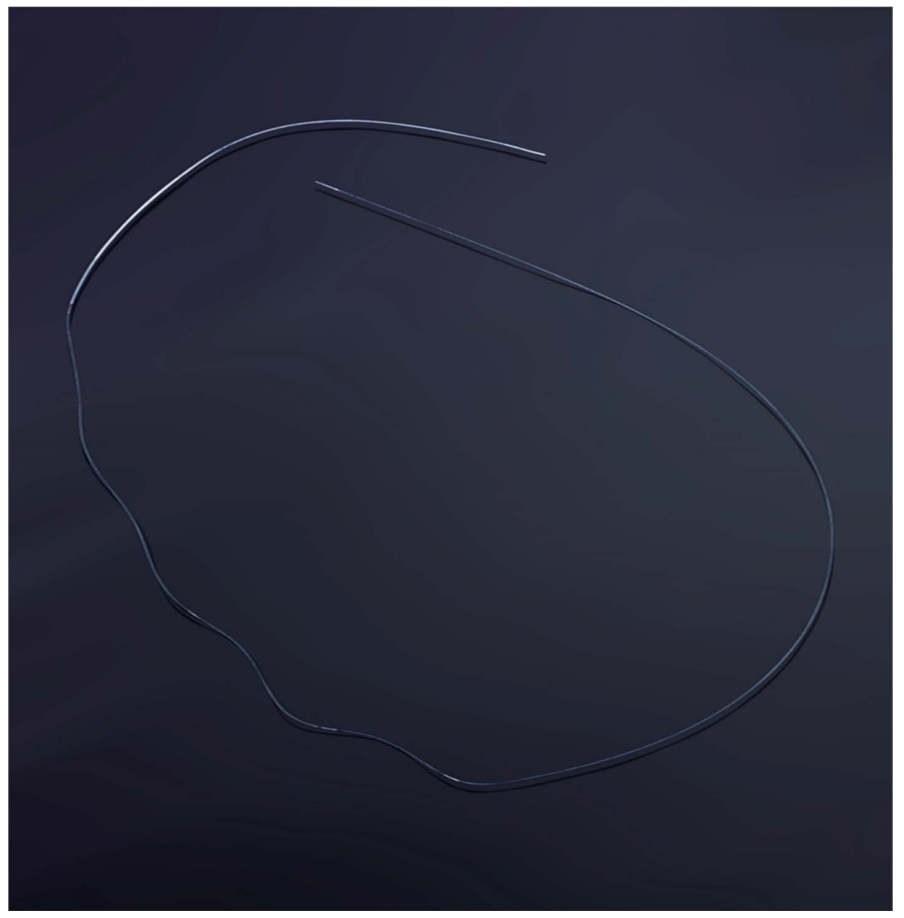

Figure 3. Deformed BMW wire.

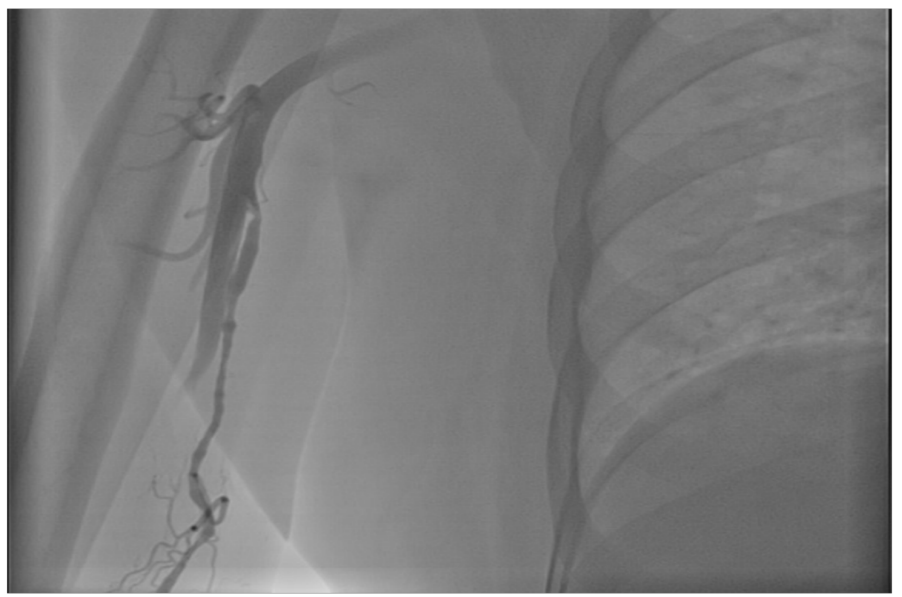

Figure 4. High origin of the radial artery in relation to upper $3^{\text {rd }}$ of humerus. A significant spasm of the radial artery is also observed.

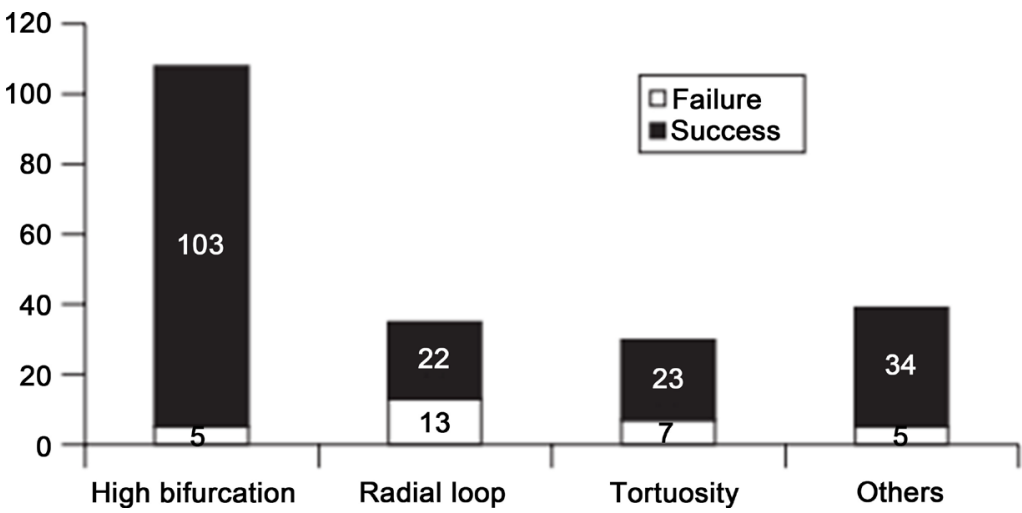

Figure 5. Types of radial anomaly and their rates of procedural failure [3]. 
Table 1. Variations of patients and procedural data in relation to radial artery anatomy [3].

\begin{tabular}{cccccc}
\hline & $\begin{array}{c}\text { Normal } \\
\text { anatomy }\end{array}$ & $\begin{array}{c}\text { High } \\
\text { bifurcations }\end{array}$ & RA loops & $\begin{array}{c}\text { Tortuous } \\
\text { RA }\end{array}$ & $\begin{array}{c}\text { Other } \\
\text { anomalies }\end{array}$ \\
\hline Patients, (n) & 1321 & 108 & 35 & 30 & 39 \\
Women (\%) & 28 & $29 \mathrm{f}$ & $49 \ddagger$ & $50 \neq$ & $33 \mathrm{\digamma}$ \\
Age (years), mean (SD) & $63.0(11.0)$ & $65.5(10.8) \mathrm{f}$ & $69.8(10.4) \S$ & $72.2(7.7) \S$ & $65.1(11.8) \mathrm{f}$ \\
$\begin{array}{c}\text { Procedural duration } \\
\text { (min), mean (SD) }\end{array}$ & $41.3(21.5)$ & $45.2(23.2) \mathrm{f}$ & $49.4(17.1) \mathrm{f}$ & $41.0(12.7) \mathrm{f}$ & $42.1(19.2) \mathrm{f}$ \\
$\begin{array}{c}\text { Fluoroscopy time (min), } \\
\text { mean (SD) }\end{array}$ & $9.7(8.0)$ & $9.3(6.5) \mathrm{f}$ & $10.0(6.6) \mathrm{f}$ & $10.7(6.5) \mathrm{f}$ & $9.6(7.1) \mathrm{f}$ \\
$\begin{array}{c}\text { Failures (\%)** } \\
\text { (m) }\end{array}$ & 0.9 & $4.6 \mathrm{f}$ & $37.1 \S$ & $23.3 \mathrm{~g}$ & $12.9 \% \mathrm{f}$ \\
\hline
\end{tabular}

${ }^{*} \mathrm{p}$ value comparing radial anomaly with normal anatomy provided when relevant; $\mathrm{tp}=\mathrm{NS}, \neq \mathrm{p}<0.05, \$ \mathrm{p}<$ $0.001,5 \mathrm{p}<0.005 ;{ }^{* *}$ Percentage of failure to radial artery anatomical finding.

to this line is considered a variant pattern. A high-bifurcating origin is further sub classified into lower third of humerus, middle third of humerus, upper third of humerus or axillary according to the site of anastomosis with the main vessel. In a study by T. S. Lo et al. majority of high radial artery origin were at the level of mid or upper humerus [3]. Our case also had origin at the level of upper third of humerus. Majority of these vessels in study by T. S. Lo et al. were of small caliber with over $85 \%$ being less than $3 \mathrm{~mm}$ in diameter [3]. Importantly, a high bifurcating radial was not associated with a high incidence of procedure failure. Lesser instances of transradial failure in that study were attributed to use of $5 \mathrm{~F}$ catheters with hydrophilic wires to complete the procedure without inducing spasm.

The origin of high bifurcating radial artery described in our case report was at the level of upper third of humerus. Also the anomalous artery was a small caliber vessel $(<3 \mathrm{~mm})$. Though check angiogram could be performed, extreme difficulty was encountered in maneuvering the guide wire and balloons. Retrograde arteriography of the vessel after withdrawal of guiding catheter from the system also showed significant spasm of the vessel soon after its origin. Use of a $6 \mathrm{~F}$ guiding catheter may have precipitated spasm in the small caliber anomalous radial artery. Unlike in the study by $T$. S. Lo et al. where all patients undergoing transradial procedures were routinely subjected to retrograde radial arteriography to define radial artery anatomy [3], anomalous radial origin in our case was noted only after encountering difficulty in maneuvering guide wire and balloons. Retrograde radial arteriography was extremely helpful in planning appropriate strategy. In view of significant spasm, to avoid potential vascular complications, transradial procedure was deferred and PTCA was completed through transfemoral approach.

\section{Conclusion}

Retrograde radial arteriography helps to delineate underlying anomalies, identifying patients with unfavorable anatomy and thereby helping the operator to 
plan a strategy to overcome the anomaly or change access route with potential to save time and avoid vascular complications. Whether, this has to be considered routinely during all transradial procedures or when confronted with technical difficulty is a matter of debate.

\section{Conflict of Interest}

The authors declare that no conflict of interest exists.

\section{References}

[1] Kiemeneij, F., Laarman, G.J., Odekerken, D., Slagboom, T. and van der Wieken, R.A. (1997) Randomized Comparison of Percutaneous Transluminal Coronary Angioplasty by the Radial, Brachial and Femoral Approaches: The Access Study. Journal of the American College of Cardiology, 29, 1269-1275.

[2] Agostoni, P., Biondi-Zoccai, G.G., De Benedictis, M.L., Rigattieri, S., Turri, M., Anselmi, M., et al. (2004) Radial versus Femoral Approach for Percutaneous Coronary Diagnostic and Interventional Procedures: Systematic Overview and Meta-Analysis of Randomized Trials. Journal of the American College of Cardiology, 44, 349-356.

[3] Lo, T.S., Nolan, J., Fountzopoulos, E., Behan, M., Butler, R., Hetherington, S.L., et al. (2009) Radial Artery Anomaly and Its Influence on Transradial Coronary Procedural Outcome. Heart, 95, 410-415. https://doi.org/10.1136/hrt.2008.150474

[4] Ludman, P.F., Stephens, N.G., Harcombe, A., Lowe, M.D., Shapiro, L.M., Schofield, P.M., et al. (1997) Radial versus Femoral Approach for Diagnostic Coronary Angiography in Stable Angina Pectoris. The American Journal of Cardiology, 79, 1239 1241. https://doi.org/10.1016/S0002-9149(97)00089-1

[5] Barbeau, G.R. (2003) Radial Loop and Extreme Vessel Tortuosity in the Transradial Approach: Advantage of Hydrophilic-Coated Guidewires and Catheters. Catheterization and Cardiovascular Interventions, 59, 442-450. https://doi.org/10.1002/ccd.10586

[6] Rodriguez-Baeza, A., Nebot, J., Ferreira, B., Reina, F., Perez, J., Sanudo, J., et al. (1995) An Anatomical Study and Ontogenetic Explanation of 23 Cases with Variations in the Main Pattern of the Human Brachio-Antebrachial Arteries. Journal of Anatomy, 187, 473.

[7] Rodríguez Niedenführ, M., Vazquez, T., Nearn, L., Ferreira, B., Parkin, I. and Sanudo, J. (2001) Variations of the Arterial Pattern in the Upper Limb Revisited: A Morphological and Statistical Study, with a Review of the Literature. Journal of Anatomy, 199, 547-566. https://doi.org/10.1046/j.1469-7580.2001.19950547.x

[8] Uglietta, J.P. and Kadir, S. (1989) Arteriographic Study of Variant Arterial Anatomy of the Upper Extremities. Cardiovascular and Interventional Radiology, 12, 145 148. https://doi.org/10.1007/BF02577379

[9] Yoo, B.-S., Yoon, J., Ko, J.-Y., Kim, J.-Y., Lee, S.-H., Hwang, S.-O., et al. (2005) Anatomical Consideration of the Radial Artery for Transradial Coronary Procedures: Arterial Diameter, Branching Anomaly and Vessel Tortuosity. International Journal of Cardiology, 101, 421-427. https://doi.org/10.1016/j.ijcard.2004.03.061 
Submit or recommend next manuscript to SCIRP and we will provide best service for you:

Accepting pre-submission inquiries through Email, Facebook, LinkedIn, Twitter, etc. A wide selection of journals (inclusive of 9 subjects, more than 200 journals)

Providing 24-hour high-quality service

User-friendly online submission system

Fair and swift peer-review system

Efficient typesetting and proofreading procedure

Display of the result of downloads and visits, as well as the number of cited articles Maximum dissemination of your research work

Submit your manuscript at: http://papersubmission.scirp.org/

Or contact wicd@scirp.org 